\title{
The influence of native aortic valve calcium and transcatheter valve oversize on the need for pacemaker implantation after transcatheter aortic valve insertion
}

Fu'ad Al-Azzam, MB, BCh, ${ }^{\mathrm{a}}$ Kevin L. Greason, MD, ${ }^{\mathrm{a}}$ Chayakrit Krittanawong, MD, ${ }^{\mathrm{b}}$ Eric E. Williamson, MD, ${ }^{\mathrm{c}}$ Christopher J. McLeod, MB, ChB, PhD, ${ }^{\mathrm{b}}$ Katherine S. King, MS, ${ }^{\mathrm{d}}$ and Verghese Mathew, MD ${ }^{\mathrm{b}, \mathrm{c}}$

\begin{abstract}
Objective: Native aortic valve calcium and transcatheter aortic valve oversize have been reported to predict pacemaker implantation after transcatheter aortic valve insertion. We reviewed our experience to better understand the association.

Methods: We retrospectively reviewed the records of 300 patients with no prior permanent pacemaker implantation who underwent transcatheter aortic valve insertion from November 2008 to February 2015. Valve oversize was calculated using area. The end point of the study was 30-day postoperative pacemaker implantation.
\end{abstract}

Results: Patient data included age of $81.1 \pm 8.4$ years, female sex in 135 patients $(45 \%)$, atrial fibrillation in 74 patients $(24.7 \%)$, Society of Thoracic Surgeons predicted risk of mortality of $7.6 \%$ (interquartile range [IQR], 5.3-10.6), aortic valve calcium score of 2568 (IQR, 1775-3526) Agatston units, and annulus area of $471 \pm 82 \mathrm{~mm}^{2}$. Balloon-expandable valves were inserted in 244 patients $(81.3 \%)$. Transcatheter aortic valve oversize was $12.8 \%$ (IQR, 3.9-23.3). Pacemaker implantation was performed in 59 patients $(19.7 \%)$. Aortic valve calcium score (adjusted $P=.275$ ) and transcatheter valve oversize (adjusted $P=.833$ ) were not independent risk factors for pacemaker implantation when controlling for preoperative right bundle branch block (adjusted odds ratio, 3.49; 95\% confidence interval, 1.61-8.55; $P=.002$ ), implantation of self-expanding valve (adjusted odds ratio, 4.09; 95\% confidence interval, 1.53-10.96; $P=.005$ ), left bundle branch block (adjusted $P=.331$ ), previous percutaneous coronary intervention (adjusted $P=.053$ ), or valve surgery (adjusted $P=.111$ ), and PR interval (adjusted $P=.350$ ).

Conclusions: Right bundle branch block and implantation of a self-expanding prosthesis were predictive of pacemaker implantation, but not native aortic valve score or transcatheter valve oversize. (J Thorac Cardiovasc Surg 2017;153:1056-62)

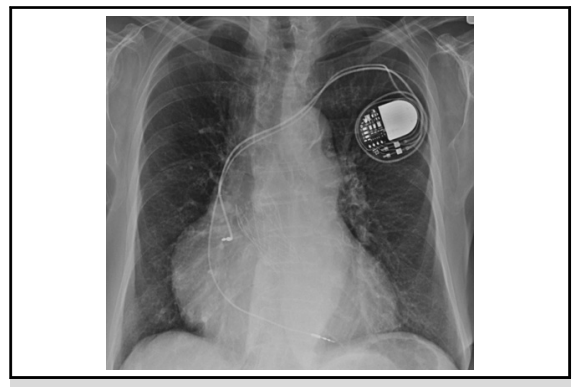

Chest $x$-ray in a patient who received a selfexpanding valve followed by permanent pacemaker insertion.

\section{Central Message}

The calcium score of the aortic valve leaflets and annulus was not associated with high incidence of heart block post-TAVI.

\section{Perspective}

Patients who are consulted for TAVI should be consulted for pacemaker insertion during the same admission specially if self-expanding devices are used.

See Editorial Commentary page 1063.
Permanent pacemaker implantation occurs in approximately $30 \%$ of patients as a complication of transcatheter aortic valve insertion (TAVI). ${ }^{1-4}$ Because some degree of

From the Divisions of ${ }^{\mathrm{a} C a r d i o v a s c u l a r ~ S u r g e r y, ~}{ }^{\mathrm{b}}$ Cardiovascular Diseases, and ${ }^{\mathrm{d}}$ Biomedical Statistics and Informatics, and ${ }^{\mathrm{c}}$ Department of Radiology, Mayo Clinic, Rochester, Minn.

Received for publication Feb 29, 2016; revisions received Oct 22, 2016; accepted for publication Nov 10, 2016; available ahead of print Jan 7, 2017.

Address for reprints: Kevin L. Greason, MD, Division of Cardiovascular Surgery, Mayo Clinic, Rochester, MN 55905 (E-mail: greason.kevin@mayo.edu).

$0022-5223 / \$ 36.00$

Copyright $(\odot 2016$ by The American Association for Thoracic Surgery

http://dx.doi.org/10.1016/j.jtcvs.2016.11.038 transcatheter valve oversize is needed to securely seat the prosthesis, it is not surprising some studies support that the amount of transcatheter valve oversize and aortic valve calcium are directly associated with postoperative pacemaker implantation. ${ }^{5-9}$ It was our hypothesis that

Scanning this QR code will take you to supplemental tables for this article.

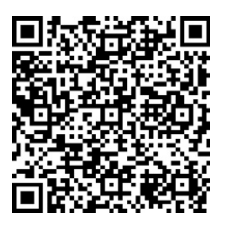



Abbreviations and Acronyms
$\mathrm{CI}=$ confidence interval
$\mathrm{CT}=$ computed tomography
$\mathrm{IQR}=$ interquartile range
$\mathrm{OR}=$ odds ratio
STS $=$ Society of Thoracic Surgeons
$\mathrm{TAVI}=$ transcatheter aortic valve insertion

transcatheter valve oversize and aortic valve calcium score would influence the need for pacemaker implantation. We reviewed our single-center experience to better characterize the effect these factors had on postoperative pacemaker implantation.

\section{MATERIALS AND METHODS}

The purpose of this study was to determine whether transcatheter aortic valve oversize and native aortic valve calcium were predictive of pacemaker implantation after TAVI. We proposed a multivariate model using the 2 variables and controlling for factors previous identified from the literature to be associated with pacemaker implantation. The Mayo Clinic Institutional Review Board approved this study.

We retrospectively reviewed the records of 435 patients without a previous permanent pacemaker who underwent TAVI between November 2008 and February 2015. There were 126 patients (29.6\%) excluded from study because of inadequate computed tomography (CT) scan data, which included patients who were part of the PARTNER studies that did not initially require specific CT scan analysis of the aortic valve and left ventricular outflow tract. ${ }^{1,2,10}$ An additional 9 patients $(2.1 \%)$ were excluded from the study because of operation-related death. A total of 300 patients were entered into the study, and all patients received TAVI under general anesthesia (Figure 1).

Baseline patient, electrocardiography, and operative characteristics and 30-day outcome data were abstracted from the Division of Cardiovascular Surgery database and individual patient electronic medical records. Baseline patient characteristics were defined as outlined in the Society of Thoracic Surgeons Adult Cardiac Surgery Database (Society of Thoracic Surgeons, Chicago, Ill). Balloon-expandable valves were sized on the basis of CT-derived aortic valve annulus area, and self-expanding valves were sized on the basis of CT-derived aortic valve annulus perimeter. ${ }^{11,12}$

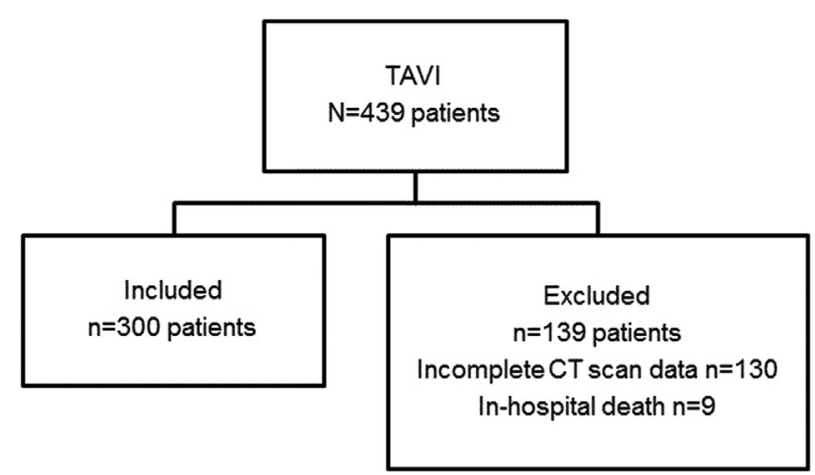

FIGURE 1. Consort diagram of study population. TAVI, Transcatheter aortic valve insertion.
All patients received a preoperative electrocardiography-gated CT scan of the heart, first without contrast and then with contrast. Calcium quantification was performed using semiautomated software (Syngovia, Siemens Healthcare, Erlangen, Germany) and reported as Agatston units. Native aortic valve annulus area and perimeter were derived using the semiautomated polygon tool (Aquarius iNtuition, TeraRecon, Foster City, Calif) using hand placement of seed points oriented to the plane of the native aortic valve cusp tips.

Valve area oversize was determined on the basis of the equation ([prosthetic aortic valve area $\div$ native aortic valve annulus area] -1$) \times 100 .{ }^{13}$ Perimeter oversize was determined on the basis of a similar equation: ([prosthetic aortic valve perimeter $\div$ native aortic valve annulus perimeter] -1$) \times 100$. Transcatheter prosthetic aortic valve areas and perimeters are reported in Table 1.

Descriptive statistics for categoric variables are reported as count (percentage) and continuous variables as mean \pm standard deviation when normally distributed or median (interquartile range [IQR]) when not normally distributed. Chi-square test, Student $t$ test, and Wilcoxon rank-sum test were used to test associations of baseline characteristics and valve type.

Native aortic valve calcium score and transcatheter valve oversize along with other electrocardiography and valve characteristics identified with pacemaker implantation in previous studies and any additional univariate significant variables were included in a multivariable logistic model. The cohort also was stratified by valve type (ie, self-expanding) to account for the difference in oversize calculation method (eg, area vs perimeter) while controlling for bundle branch block. Data were analyzed with SAS statistical software version 9.4 (SAS Institute, Inc, Cary, NC). An alpha level of 0.05 was used to determine statistical significance.

\section{RESULTS}

Baseline patient characteristics included an age of $81.1 \pm 8.4$ years, female sex in 135 patients $(45.0 \%)$, and a Society of Thoracic Surgeons predicted risk of mortality of 7.6\% (IQR, 5.3-10.6). Additional baseline patient data are presented in Table 2. The aortic valve calcium score was 2568 (IQR, 1775-3528) Agatston units, and native aortic valve area was $471 \pm 82 \mathrm{~mm}^{2}$.

Atrial fibrillation was present in 74 patients $(24.7 \%)$. In the 226 patients with sinus rhythm, the mean PR interval was $184 \mathrm{~ms}$ (IQR, 162-208), and 66 patients (29.2\%) had a PR interval greater than $200 \mathrm{~ms}$. For all patients, the QRS duration was $100 \mathrm{~ms}$ (IQR, 92-118), and 71 patients $(23.7 \%)$ had a QRS duration greater than $120 \mathrm{~ms}$. Right bundle branch block was present in 45 patients $(15 \%)$, and left bundle branch block was present in 25 patients $(8.3 \%)$.

TAVI access was transfemoral in 174 patients $(58.0 \%)$, transapical in 113 patients $(37.7 \%)$, transaortic in 12 patients $(4.0 \%)$, and transaxillary in 1 patient $(0.3 \%)$. Balloon-expandable valves were inserted in 244 patients $(81.3 \%)$, and self-expanding valves were inserted in $56 \mathrm{pa}-$ tients $(18.7 \%)$. Specific valve types included the SAPIEN valve (Edwards Lifesciences, Irvine, Calif) in 131 patients (43.7\%), SAPIEN XT valve (Edwards Lifesciences) in 69 patients $(23.0 \%)$, SAPIEN S3 valve (Edwards Lifesciences) in 44 patients $(14.7 \%)$, and CoreValve (AccuTrak, Medtronic, Minneapolis, Minn) in 56 patients (18.7\%). 
TABLE 1. Transcatheter prosthetic aortic valve area stratified by valve type and size

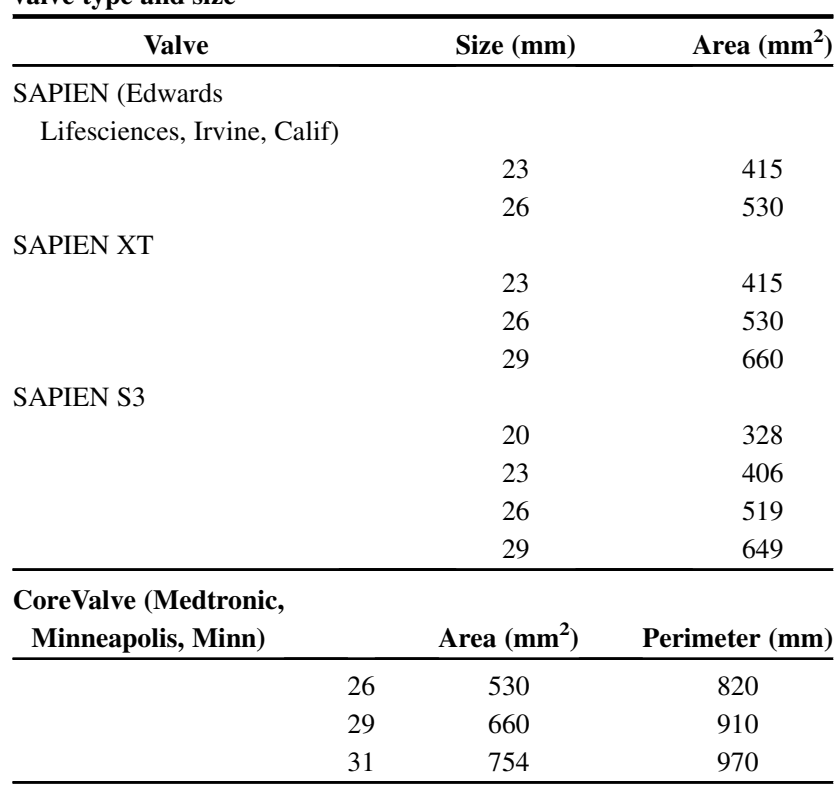

Baseline characteristics were similar in patients who received balloon or self-expanding transcatheter prosthetic aortic valve insertion (Table 3). Baseline PR interval was less in the balloon-expandable group (184; IQR, 164-210) than in the self-expanding group (173; IQR, 154-199; $P=.048$ ), but there was no difference in the number of patients with PR interval greater than $200 \mathrm{~ms}(P=.219)$. Right bundle branch block was present in 39 patients $(16.0 \%)$ in the balloon-expandable valve group and in 6 patients $(10.7 \%)$ in the self-expanding valve group $(P=.319)$. The prevalence of left bundle branch block was similar in the 2 groups $(P=.475)$.

CT findings were similarly distributed among the balloon-expandable and self-expanding valve insertion groups (Table 3). This specifically included aortic valve calcium score that measured 2569 (IQR, 1805-3553) Agatston units in the balloon-expandable valve group and 2509 (IQR, 1684-3460) Agatston units in the self-expanding valve group $(P=.488)$. The native aortic valve area measured $467 \pm 78 \mathrm{~mm}^{2}$ in the balloon-expandable valve group and $487 \pm 99 \mathrm{~mm}^{2}$ in the self-expanding valve group $(P=.139)$.

Aortic valve oversize in the balloon-expandable group was $9.6 \%$ (IQR, 1.8-15.9). It is important to note that the self-expanding group was sized by perimeter, and the amount of perimeter oversize was $13.8 \%$ (IQR, 7.8-17.5); when this group was analyzed by area, the amount of area oversize was $40.0 \%$ (IQR, 27.0-57.1). The difference in the amount of oversize by area was significant between the 2 valve type groups $(P<.001)$.
TABLE 2. Baseline patient characteristics

\begin{tabular}{|c|c|}
\hline Continuous variables & \\
\hline Age $(y)$ & $81.1 \pm 8.4$ \\
\hline Creatinine, last before operation $(\mathrm{mg} / \mathrm{dL})$ & $1.1(\mathrm{IQR}, 0.9-1.4)$ \\
\hline Ejection fraction $(\%)$ & $62(\mathrm{IQR}, 51-66)$ \\
\hline STS predicted risk of mortality $(\%)$ & 7.6 (IQR, 5.3-10.6) \\
\hline Categoric variables & Count $(\%)$ \\
\hline Female sex & $135(45)$ \\
\hline Diabetes & $122(40.7)$ \\
\hline Hypertension & $270(90.0)$ \\
\hline Dialysis & $8(2.7)$ \\
\hline Chronic lung disease & $182(60.7)$ \\
\hline Mild & $76(25.3)$ \\
\hline Moderate & $46(15.3)$ \\
\hline Severe & $60(20.0)$ \\
\hline Immunosuppression & $49(16.3)$ \\
\hline Peripheral vascular disease & $199(66.3)$ \\
\hline Cerebrovascular disease & $71(23.7)$ \\
\hline Previous coronary artery bypass graft operation & $102(34.0)$ \\
\hline Previous valve procedure & $58(19.3)$ \\
\hline Previous percutaneous coronary intervention & $140(46.7)$ \\
\hline Previous myocardial infarction & $89(29.7)$ \\
\hline NYHA class III or IV & $254(84.7)$ \\
\hline Atrial arrhythmia & $74(24.7)$ \\
\hline Right bundle branch block & $45(15.0)$ \\
\hline Left bundle branch block & $25(8.3)$ \\
\hline No. of diseased vessels $\geq 1$ & $206(68.7)$ \\
\hline Left main coronary artery stenosis & $46(15.3)$ \\
\hline Aortic valve stenosis & $300(100.0)$ \\
\hline Mitral valve stenosis & $59(19.7)$ \\
\hline Aortic valve regurgitation moderate or severe & $40(13.3)$ \\
\hline Mitral valve regurgitation moderate or severe & $65(21.7)$ \\
\hline Tricuspid valve regurgitation moderate or severe & $58(19.8)$ \\
\hline Previous cardiac operation & $112(37.3)$ \\
\hline Status elective operation & $292(97.3)$ \\
\hline
\end{tabular}

Postoperative permanent pacemaker implantation was performed in 59 patients $(19.7 \%)$. Specific valve type and pacemaker implantation rates are reported in Table E1. The most common indication for pacemaker implantation was advanced atrioventricular block to include complete and high-degree atrioventricular block, which was present in 38 patients $(64.4 \%)$. The most common device inserted was a dual-chamber right ventricular pacemaker in 41 patients $(69.5 \%)$. Additional data about pacemaker implantation indications and type of device inserted are reported in Table E2.

Valve area oversize (\%) (unadjusted $P=.004)$ and aortic valve calcium score (unadjusted $P=.226$ ) were assessed in a multivariable logistic regression model to control for confounding baseline electrocardiography and valve characteristics known to be associated with pacemaker implantation from previous studies and our 
TABLE 3. Baseline patient characteristics stratified by transcatheter prosthetic aortic valve insertion type

\begin{tabular}{|c|c|c|c|}
\hline Continuous variables & Balloon expandable $(n=244,81.3 \%)$ & Self-expanding $(n=56,18.7 \%)$ & $P$ value \\
\hline Age $(y)$ & $81.2 \pm 8.5$ & $80.6 \pm 8.1$ & .641 \\
\hline STS predicted risk of mortality $(\%)$ & $7.5(\mathrm{IQR}, 5.2-9.9)$ & 8.4 (IQR, 5.6-12.0) & .066 \\
\hline CT scan aortic valve calcium score (Agatston unit) & 2569 (IQR, 1805-3553) & 2509 (IQR, 1634-3460) & .488 \\
\hline CT scan-derived aortic valve area $\left(\mathrm{mm}^{2}\right)$ & $467 \pm 78$ & $487 \pm 99$ & .110 \\
\hline PR interval (ms) & $184(\mathrm{IQR}, 164-210)$ & 173 (IQR, 143-199) & .048 \\
\hline QRS interval (ms) & 102 (IQR, 92-122) & 96 (IQR, 88-113) & .082 \\
\hline Prosthetic valve oversize $(\%)$ & 9.6 (IQR, 1.8-16.0) & 40.0 (IQR, 26.9-57.1) & $<.001$ \\
\hline Categoric variables & Count $(\%)$ & & \\
\hline Female sex & $115(47.1)$ & $20(35.7)$ & .121 \\
\hline Diabetes & $150(61.5)$ & $28(50.0)$ & .115 \\
\hline Previous valve procedure & $47(19.3)$ & $11(19.6)$ & .948 \\
\hline Atrial fibrillation & $60(24.6)$ & $14(25.0)$ & .949 \\
\hline PR interval $\geq 200 \mathrm{~ms}$ & $57(31.0)$ & $9(21.4)$ & .219 \\
\hline QRS interval $\geq 120 \mathrm{~ms}$ & $62(25.4)$ & $9(16.1)$ & .138 \\
\hline Right bundle branch block & $39(16.0)$ & $6(10.7)$ & .319 \\
\hline Left bundle branch block & $19(7.8)$ & $6(10.7)$ & .475 \\
\hline
\end{tabular}

Where mean \pm standard deviation shown, Student $t$ test was used. STS, Society of Thoracic Surgeons; IQR, interquartile range; $C T$, computed tomography.

univariate findings. Previous findings suggested including preoperative PR duration greater than $200 \mathrm{~ms}$ (with atrial fibrillation), left bundle branch block, right bundle branch block, and self-expanding valve. Previous valve surgery (odds ratio [OR], $0.41 ; 95 \%$ confidence interval [CI], $0.17-1.01 ; P=.053)$ and previous percutaneous intervention (OR, 1.89 ; $95 \% \mathrm{CI}, 1.06-3.37 ; P=.031)$ were associated with pacemaker implantation in our univariate analysis. These 6 variables plus aortic valve calcium score and valve area oversize are shown in multivariable model in Table 4.

The functional forms of valve oversize area and aortic valve calcium score were assessed; the $\log$ form of aortic valve calcium score and the untransformed valve oversize area were found to be most appropriate. Aortic valve calcium score (adjusted $P=.275$ ) and valve area oversize (adjusted $P=.833$ ) were found not to be independently associated with pacemaker implantation. Insertion of a self-expanding transcatheter prosthetic aortic valve was predictive of permanent pacemaker implantation (adjusted OR, 4.09; 95\% CI, 1.53-10.96) along with right bundle branch block (adjusted OR, 3.49; 95\% CI, 1.61-7.55). However, PR interval greater than $200 \mathrm{~ms}$, previous valve surgery, previous percutaneous intervention, and left bundle branch block were not associated with pacemaker implantation (Table 4).

In univariate analysis, valve oversize was associated with pacemaker implantation (OR, 1.02; 95\% CI, 1.01-1.03; $P=.004)$, but this association disappeared when controlling for self-expanding valve. The interaction of self-expanding valve and valve area oversize in the multivariable model was considered but was not significant $(P=.73)$; however, valve oversize between the 2 groups

TABLE 4. Estimated adjusted odds ratios and $95 \%$ confidence interval estimates for preoperative left bundle branch block, right bundle branch block, self-expanding valve, valve area oversize (\%), aortic valve calcium score (Agatston score), and PR duration greater than 200 milliseconds (with atrial fibrillation) $(\mathrm{n}=\mathbf{3 0 0})$

\begin{tabular}{|c|c|c|c|c|}
\hline \multirow[b]{2}{*}{ Variable } & \multirow[b]{2}{*}{ OR } & \multicolumn{2}{|c|}{ 95\% Wald CI } & \multirow[b]{2}{*}{$P$ value } \\
\hline & & Low & High & \\
\hline Left bundle branch block (yes or no) & 1.69 & 0.59 & 4.87 & .331 \\
\hline Right bundle branch block (yes or no) & 3.49 & 1.61 & 7.55 & .002 \\
\hline Self-expanding valve (yes or no) & 4.09 & 1.53 & 10.96 & .005 \\
\hline Valve oversize area $(\%)$ & 1.00 & 0.98 & 1.02 & .83 \\
\hline Aortic valve calcium score (500 unit increase) & 1.05 & 0.96 & 1.15 & .275 \\
\hline PR duration $>200 \mathrm{~ms}$ (atrial fibrillation vs no) & 1.34 & 0.63 & 2.77 & .350 \\
\hline PR duration $>200 \mathrm{~ms}$ (yes or no) & 1.76 & 0.81 & 3.83 & \\
\hline Previous valve surgery & 0.46 & 0.18 & 1.20 & .111 \\
\hline Previous percutaneous coronary intervention & 1.85 & 0.99 & 3.43 & 053 \\
\hline
\end{tabular}

$O R$, Odds ratio; $C I$, confidence interval. 
TABLE 5. Estimated adjusted odds ratios and $95 \%$ confidence interval estimates for right bundle branch block and valve area oversize (\%) for subjects with balloon-expandable valves $(n=244)$

\begin{tabular}{lllll}
\hline & & \multicolumn{2}{c}{$\mathbf{9 5 \% \text { Wald CI }}$} & \\
\cline { 3 - 4 } Variable & OR & Low & High & P value \\
\hline $\begin{array}{l}\text { Right bundle branch block } \\
\text { (yes or no) }\end{array}$ & 4.55 & 2.06 & 10.04 & $<.001$ \\
\begin{tabular}{l} 
Valve oversize area \\
\hline
\end{tabular} & 0.99 & 0.96 & 1.02 & .590 \\
\hline
\end{tabular}

$O R$, Odds ratio; $C I$, confidence interval.

before surgery was determined with different calculation methods (ie, area or perimeter).

Logistic regression was performed individually for balloon-expanding and self-expanding valves comparing valve oversize using the area oversize and perimeter oversize, respectively, while controlling for right bundle branch block. Valve oversize was not significantly associated with pacemaker implantation in either group, balloonexpandable (adjusted OR, 0.99; 95\% CI, 0.96-1.02; $P=.599$ ) for oversize area and self-expanding (adjusted OR, $1.04 ; 95 \%$ CI, $0.96-1.13 ; P=.320$ ) for perimeter oversize, as shown in Tables 5 and 6.

There were 126 patients $(29.6 \%)$ who were excluded from the study because of incomplete CT scan data. Table E3 contains specific data of baseline patient characteristics, operative data, and outcomes from these patients compared with the 300 patients $(70.4 \%)$ included in the study.

\section{DISCUSSION}

The focus of this study was to test whether aortic valve oversize and calcium score were predictive of permanent pacemaker implantation after TAVI. In this series of $300 \mathrm{pa}-$ tients, pacemaker implantation was performed in 59 patients $(19.6 \%)$. Standard logistic regression analysis was performed of baseline patient electrocardiographic and valve characteristics to identify those variables associated with pacemaker implantation. Multivariable analysis identified that baseline right bundle branch block and insertion of the self-expanding transcatheter valve were variables independently associated with pacemaker implantation. In contrast, aortic valve oversize and calcium score were not predictive of pacemaker implantation.

TABLE 6. Estimated adjusted odds ratios and 95\% confidence interval estimates for right bundle branch block and valve perimeter oversize $(\%)$ for subjects with self-expanding valve $(n=56)$

\begin{tabular}{ccccc}
\hline & & \multicolumn{2}{c}{$\mathbf{9 5 \% \text { Wald CI }}$} & \\
\cline { 3 - 4 } Variable & OR & Low & High & P value \\
\hline $\begin{array}{l}\text { Right bundle branch block } \\
\text { (yes or no) }\end{array}$ & 1.45 & 0.26 & 8.16 & .674 \\
\begin{tabular}{l} 
Valve oversize perimeter \\
\hline
\end{tabular} & 1.04 & 0.96 & 1.13 & .320 \\
\hline
\end{tabular}

$O R$, Odds ratio; $C I$, confidence interval.
There is controversy in the literature whether aortic valve calcium score is related to permanent pacemaker implantation after transcatheter valve insertion. Latsios and colleagues ${ }^{8}$ demonstrated that device landing zone calcification was predictive of permanent pacemaker implantation (OR, 1.06; 95\% CI, 1.02-1.11; $P=.004)$, but there were only 81 patients in that study. Although Haensig and colleagues ${ }^{9}$ reported a "trend towards a higher incidence of new pacemaker implantation" (OR, $1.27 ; 95 \%$ CI, 0.85-1.89), specific review of the article demonstrates that the finding was not significant $(P=.26)$. It may be that the aortic valve calcium score is too generalized a measurement, and that it is specific calcification around the area of the membranous septum and atrioventricular conduction system that is important. At present, the current weight of evidence supports no interaction between the aortic valve calcium score and the need for permanent pacemaker implantation after TAVI.

We also noted no relationship between permanent pacemaker implantation and valve area oversize. Similar results were reported by Bleiziffer and colleagues, ${ }^{14}$ who noted no association with annulus-to-valve size difference $(P=.113)$. In the study referenced by Nazif and colleagues ${ }^{5}$ with the PARTNER Trial and Registry, however, permanent pacemaker implantation was predicted by prosthesis diameter/left ventricular outflow tract diameter (for each 0.1 increment, OR, 1.29; 95\% CI, 1.10-1.51; $P=.002$ ). But Nazif and colleagues' study was limited to only balloonexpandable valves, and the left ventricular outflow tract diameter was determined with a single plane echocardiography measurement, not with electrocardiography-gated multidetector CT measurement of the aortic valve area, as in the current study.

Postoperative permanent pacemaker implantation is more common after TAVI of a self-expanding valve in comparison with a balloon-expandable valve. The finding is corroborated by our data and in the CHOICE randomized clinical trial reported by Abdel-Wahab and colleagues, ${ }^{15}$ who demonstrated that placement of a new permanent pacemaker was less frequent after balloon-expandable valve insertion $(17.3 \%)$ in comparison with self-expanding valve insertion $(37.6 \% ; P=.001)$. Additional support comes from the Cleveland Clinic group, who published a recent meta-analysis on approximately 30,000 patients undergoing transcatheter valve insertion. ${ }^{16}$ In that study, the pooled incidence rates for permanent pacemaker implantation were $6.2 \%$ (95\% CI, 5.4-7.0) for balloon-expandable valves and $24.3 \%$ (95\% CI, 20.6-28.1) for self-expanding valves.

Acknowledged reasons for the increased risk of postoperative pacemaker implantation with self-expanding valves are that the prosthesis deploys lower in the left ventricular outflow tract and that continuous outward 
radial force of the prosthesis can result in injury to the atrioventricular conduction system. ${ }^{17}$ It is interesting that in our study, the self-expanding valves had significantly greater amount of valve area oversize (4.6-fold greater) in comparison with the balloon-expandable valves. Although we demonstrated that the amount of area oversize did not predict the need for permanent pacemaker implantation, the vastly greater amount of valve area oversize is a cause for concern. It is possible that newer delivery systems (AccuTrak, Medtronic) and less implantation depth may result in a lower rate of permanent pacemaker implantation, ${ }^{18,19}$ and further study is warranted.

Our data demonstrate a direct relationship between right bundle branch block and risk of permanent pacemaker placement. Additional support of this finding comes from Koos and colleagues, ${ }^{20}$ who reported in a small series that $67 \%$ of patients with right bundle branch block received a permanent pacemaker after transcatheter valve insertion; along similar lines, Ramazzina and colleagues ${ }^{21}$ also reported a predictor of high-grade atrioventricular block was right bundle branch block (OR, 81.95; 95\% CI, 8.72770.46; $P<.001$ ). The issue remains controversial because Bleiziffer and colleagues ${ }^{14}$ noted a similar prevalence of preoperative right bundle branch block in patients with $(9 \%)$ and without $(2 \%)$ new-onset atrioventricular block $(P=.078)$. Similar to our findings, Bleiziffer and colleagues also reported no association with preoperative heart rhythm (ie, sinus rhythm vs atrial fibrillation; $P=.869$ ) or left bundle branch block $(P=.504)$.

\section{Study Limitations}

This was a single-center, retrospective analysis and therefore is subject to the biases of our multidisciplinary heart team. Although the study included 300 patients, there were only 59 events, so we were limited in how many variables could be entered into the multivariable analysis. We also recognize that more than one third of the patients received a pacemaker for reasons other than high-grade atrioventricular block, which theoretically should be independent of aortic valve calcium score or valve oversize. Our pacemaker insertion practice certainly has evolved with experience from the first to the second decile of implantation, and this bias is difficult to control for given the relatively large number of first decile patients who were excluded from study because of incomplete CT scan data (Table E3).

An additional limitation warranting discussion is that we did not address the depth of valve deployment within the left ventricular outflow tract. The depth of deployment has been shown to be related to subsequent permanent pacemaker implantation. However, we would argue that the final position of the valve is mostly important as a postoperative finding. It is our experience that before valve deployment, the position of the valve is exactly where the heart team agrees the deployment should occur. Now, the final position may not be the same because the valve moves some during deployment. There is not much that can be done about that, however, given the valves used in this study (ie, no repositionable valves).

\section{CONCLUSIONS}

Pacemaker implantation is common after TAVI and occurred in 1 of 5 patients in this study. Baseline right bundle branch block and insertion of a self-expanding transcatheter aortic prosthesis were predictive of permanent pacemaker insertion, but aortic valve calcium score and valve oversize were not. A better understanding of causation is warranted given the high prevalence of pacemaker implantation. Specifically identifying areas of high focal calcium burden in the area of the left ventricular outflow tract may be more representative of the risk of pacemaker implantation. The ability to recapture and reposition the valve in the proper location seems to be an intuitive method to reduce injury to the atrioventricular conduction system. Knowledge and technology are most likely the keys to the dilemma.

\section{Conflict of Interest Statement}

Authors have nothing to disclose with regard to commercial support.

\section{References}

1. Smith CR, Leon MB, Mack MJ, Miller DC, Moses JW, Svensson LG, et al. Transcatheter versus surgical aortic-valve replacement in high-risk patients. N Engl J Med. 2011;364:2187-98.

2. Leon MB, Smith CR, Mack MJ, Makkar RR, Svensson LG, Kodali SK, et al. Transcatheter or surgical aortic-valve replacement in intermediate-risk patients. N Engl J Med. 2016;374:1609-20.

3. Adams DH, Popma JJ, Reardon MJ, Yakubov SJ, Coselli JS, Deeb GM, et al. Transcatheter aortic-valve replacement with a self-expanding prosthesis N Engl J Med. 2014;370:1790-8.

4. Ledwoch J, Franke J, Gerckens U, Kuck KH, Linke A, Nickenig G, et al. Incidence and predictors of permanent pacemaker implantation following transcatheter aortic valve implantation: analysis from the German Transcatheter Aortic Valve Interventions Registry. Catheter Cardiovasc Interv. 2013;82 E569-77.

5. Nazif TM, Dizon JM, Hahn RT, Xu K, Babilaros V, Douglas PS, et al. Predictors and clinical outcomes of permanent pacemaker implantation after transcatheter aortic valve replacement. JACC Cardiovasc Interv. 2015;8: 60-9.

6. Kim WJ, Ko YG, Kim YH, Dy TC, Posas FE, Lee MK, et al. Predictors of permanent pacemaker insertion following transcatheter aortic valve replacement with the CoreValve revalving system based on computed tomography analysis: an Asian multicentered registry study. J Invasive Cardiol. 2015;7: $334-40$.

7. Maan A, Refaat MM, Heist EK, Passeri J, Inglessis I, Ptaszek L, et al. Incidence and predictors of pacemaker implantation in patients undergoing transcatheter aortic valve replacement. PACE. 2015;38:878-86.

8. Latsios G, Gerckens U, Buellesfeld L, Mueller R, John D, Yuecel S, et al "Device landing zone" calcification, assessed by MSCT, as predictive factor for pacemaker implantation after TAVI. Catheter Cardiovasc Interv. 2010;76: 431-9.

9. Haensig M, Lehmkuhl L, Rastan AJ, Kempfert J, Mukherjee C, Gutberlet M, et al. Aortic valve calcium scoring is a predictor of significant paravalvular aortic 
insufficiency in transapical-aortic valve implantation. Eur J Cardiothorac Surg. 2012;41:1234-40.

10. Leon MB, Smith CR, Mack M, Miller DC, Moses JW, Svensson LG, et al. Transcatheter aortic-valve implantation for aortic stenosis in patients who cannot undergo surgery. N Engl J Med. 2010;363:1597-607.

11. Blanke P, Siepe M, Reinöhl J, Zehender M, Beyersdorf F, Schlensak C, et al. Assessment of aortic annulus dimensions for Edwards SAPIEN Transapical Heart Valve implantation by computed tomography: calculating average diameter using a virtual ring method. Eur J Cardiothorac Surg. 2010;38:750-8.

12. Schwarz F, Lange P, Zinsser D, Greif M, Boekstegers P, Schmitz C, et al. CT-angiography-based evaluation of the aortic annulus for prosthesis sizing in transcatheter aortic valve implantation (TAVI)-predictive value and optimal thresholds for major anatomic parameters. PLoS One. 2014;9:e103481.

13. Dvir D, Webb JG, Piazza N, Blanke P, Barbanti M, Bleiziffer S, et al. Multicenter evaluation of transcatheter aortic valve replacement using either SAPIEN XT or CoreValve: degree of device oversizing by computer-tomography and clinical outcomes. Catheter Cardiovasc Interv. 2015;86:508-15.

14. Bleiziffer S, Ruge H, Hörer J, Hutter A, Geisbüsch S, Brockmann G, et al. Predictors for new-onset complete heart block after transcatheter aortic valve implantation. JACC Cardiovasc Interv. 2010;3:524-30.

15. Abdel-Wahab M, Mehilli J, Frerker C, Neumann FJ, Kurz T, Tölg R, et al. Comparison of balloon-expandable vs self-expandable valves in patients undergoing transcatheter aortic valve replacement: the CHOICE randomized clinical trial. JAMA. 2014;311:1503-14.

16. Agarwal S, Parashar A, Kumbhani D, Svensson LG, Krishnaswamy A, Tuzcu EM, et al. Comparative meta-analysis of balloon-expandable and selfexpandable valves for transcatheter aortic valve replacement. Int J Cardiol. 2015; 197:87-97.
17. Fraccaro C, Buja G, Tarantini G, Gasparetto V, Leoni L, Razzolini R, et al. Incidence, predictors, and outcome of conduction disorders after transcatheter self-expandable aortic valve implantation. Am J Cardiol. 2011; 107:747-54.

18. Muñoz-García AJ, Hernández-García JM, Jiménez-Navarro MF, AlonsoBriales JH, Domínguez-Franco AJ, Fernández-Pastor J, et al. Factors predicting and having an impact on the need for a permanent pacemaker after CoreValve prosthesis implantation using the new Accutrak delivery catheter system. JACC Cardiovasc Interv. 2012;5:533-9.

19. De Torres-Alba F, Kaleschke G, Diller GP, Vormbrock J, Orwat S, Radke R, et al. Changes in the pacemaker rate after transition from Edwards SAPIEN XT to SAPIEN 3 transcatheter aortic valve implantation: the critical role of valve implantation height. JACC Cardiovasc Interv. 2016;9:805-13.

20. Koos R, Mahnken AH, Aktug O, Dohmen G, Autschbach R, Marx N, et al. Electrocardiographic and imaging predictors for permanent pacemaker requirement after transcatheter aortic valve implantation. J Heart Valve Dis. 2011;20:83-90.

21. Ramazzina C, Knecht S, Jeger R, Kaiser C, Schaer B, Osswald S, et al. Pacemaker implantation and need for ventricular pacing during follow-up after transcatheter aortic valve implantation. Pacing Clin Electrophysiol. 2014;37: $1592-601$.

Key Words: transcatheter aortic valve insertion, transcatheter aortic valve replacement, aortic valve calcium score, valve oversize, complication, pacemaker, bundle branch block 
TABLE E1. Pacemaker implantation stratified by type and size of transcatheter prosthetic aortic valve insertion

\begin{tabular}{lcc}
\hline Prosthetic aortic valve type & No. at risk (\%) & Pacemaker implantation (\%) \\
\hline SAPIEN (Edwards Lifesciences, Irvine, Calif) & 131 & $16(12.2)$ \\
$23 \mathrm{~mm}$ & $44(33.6)$ & $4(9.1)$ \\
$26 \mathrm{~mm}$ & $87(66.4)$ & $12(13.8)$ \\
SAPIEN XT & 69 & $14(20.3)$ \\
$23 \mathrm{~mm}$ & $17(24.6)$ & $2(11.8)$ \\
$26 \mathrm{~mm}$ & $32(46.4)$ & $9(28.1)$ \\
$29 \mathrm{~mm}$ & $20(29.0)$ & $3(15.0)$ \\
SAPIEN S3 & 44 & $7(15.9)$ \\
$20 \mathrm{~mm}$ & $4(9.1)$ & $1(25.0)$ \\
$23 \mathrm{~mm}$ & $8(18.2)$ & 0 \\
$26 \mathrm{~mm}$ & $21(47.7)$ & $4(19.1)$ \\
$29 \mathrm{~mm}$ & $11(25)$ & $2(18.2)$ \\
CoreValve (Medtronic, Minneapolis, Minn) & 56 & $22(39.3)$ \\
$26 \mathrm{~mm}$ & $9(16.1)$ & $4(44.4)$ \\
$29 \mathrm{~mm}$ & $19(33.9)$ & $8(42.1)$ \\
$31 \mathrm{~mm}$ & $28(50.0)$ & $10(35.7)$ \\
\hline
\end{tabular}

TABLE E2. Pacemaker implantation stratified by indication and type of device

\begin{tabular}{|c|c|}
\hline Indication & Count $(\%)(\mathbf{n}=\mathbf{5 9})$ \\
\hline Advanced atrioventricular block (complete and high-degree atrioventricular block) & $38(64.4)$ \\
\hline Second-degree heart block (Mobitz type 2 and type 1 with additional conduction disturbance) & $6(10.2)$ \\
\hline Sick sinus syndrome (including tachycardia-bradycardia syndrome) & $10(17.0)$ \\
\hline Other bradycardia & $5(8.5)$ \\
\hline \multicolumn{2}{|l|}{ Type of device } \\
\hline Dual-chamber right ventricular & $41(69.5)$ \\
\hline Single-chamber right ventricular & $16(27.1)$ \\
\hline Biventricular & $1(1.7)$ \\
\hline Implantable cardioverter-defibrillator & $1(1.7)$ \\
\hline
\end{tabular}

TABLE E3. Patient characteristics stratified by inclusion and exclusion in the study

\begin{tabular}{|c|c|c|c|}
\hline Preoperative variables & Included in study $(n=300)$ & Excluded from study $(n=126)^{*}$ & $P$ value \\
\hline Atrial fibrillation & $74(25)$ & $23(18)$ & .150 \\
\hline PR interval (ms) & $184(160-208)$ & $187(160-217)$ & .467 \\
\hline QRS duration (ms) & $100(92-118)$ & $104(90-132)$ & .383 \\
\hline Right bundle branch block & $44(15)$ & $17(13)$ & .752 \\
\hline Left bundle branch block & $20(7)$ & $16(13)$ & .041 \\
\hline \multicolumn{4}{|l|}{ Operation variables } \\
\hline Valve type & & & $<.001$ \\
\hline SAPIEN & $131(44)$ & $89(71)$ & \\
\hline SAPIEN XT & $69(23)$ & $35(28)$ & \\
\hline SAPIEN S3 & $44(15)$ & $1(1)$ & \\
\hline CoreValve & $56(19)$ & $1(1)$ & \\
\hline First decile of operation experience & $13(4)$ & $64(51)$ & $<.001$ \\
\hline \multicolumn{4}{|l|}{ Postoperative variables } \\
\hline Right bundle branch block & $49(16)$ & $16(13)$ & .341 \\
\hline Postoperative left bundle branch block & $81(27)$ & $25(20)$ & .115 \\
\hline Pacemaker implantation & $59(20)$ & $7(6)$ & $<.001$ \\
\hline
\end{tabular}

*Does not include 9 patients who died in the hospital. 